\title{
FAKTOR-FAKTOR YANG MEMPENGARUHI KEPERCAYAAN DAN LOYALITAS NASABAH PERBANKAN DI SURABAYA
}

\author{
Gunarto Suhardi \\ Universitas Atma Jaya Yogyakarta
}

\begin{abstract}
Led by foreign banks operating in Indonesia, many banks have switched their main business activities from corporate banking business to individual customer banking activities. This is due to the deteriorating general economic condition in Indonesia at the present time. Individual customer's base operation for banking communities proved to be suitable and giving good returns. However, as many banks operating in the same basis, competition among banks has mounted considerably. One must be able to achieve trust and loyalty from their valued customers. This article tries to understand how bank in Surabaya should get these basic elements of trust and loyalty.
\end{abstract}

Keywords: corporate banking business, individual customer banking, trust, loyalty.

\section{PENDAHULUAN}

Berdasarkan pengamatan yang telah dilakukan selama bertugas pada sebuah bank maka terdapat fenomena yang menarik untuk diamati pada waktu sekarang ini, yakni pergeseran aktivitas perbankan dari operasi yang mendasari diri pada pelayanan perusahaan besar ke pelayanan nasabah individual. Dalam dunia perbankan di Indonesia telah terjadi perubahan yang cukup menarik yaitu bergesernya bisnis perbankan, dari perbankan yang melayani perusahaan (corporate banking) menjadi lebih fokus pada melayani perseorangan (consumer banking). Pergeseran ini terjadi setelah krisis ekonomi melanda pada tahun 1997, ketika banyak pelaku bisnis mengalami masalah serius kondisi keuangan usaha yang dijalankan. Kondisi ini nampak pada tingginya tingkat non performing loan sehingga terjadi kredit macet.

Kondisi buruk yang melanda kinerja keuangan perusahaan-perusahaan corporate tersebut mengakibatkan target market perbankan yang bergerak di bidang corporate banking menjadi menyempit. Didorong oleh keinginan untuk tetap bertahan dalam bisnis perbankan, banyak bank yang kemudian mengalihkan target marketnya kepada konsumen individual. Kecenderungan ini didukung oleh kenyataan bahwa besarnya jumlah penduduk di Indonesia merupakan potensi besar yang berhubungan erat dengan dana dari pihak ketiga.

Masalah selanjutnya, banyak perbankan yang berbondong-bondong memasuki lahan berpotensi ini mengingat kredit kepada individual terbukti lebih bertahan di tengah pergolakan ekonomi. Perbankan yang fokus pada consumer banking lebih mampu bertahan daripada perbankan yang fokus pada corporate banking. Semakin banyak bank yang beralih menggarap pasar konsumen membuat persaingan antar bank semakin tinggi. Persaingan yang ketat ini mendorong perbankan untuk menciptakan competitive advantage.

Perbankan adalah industri yang penawarannya relatif homogen. Dalam industri perbankan, bila tingkat bunga (price) merupakan satu-satunya differentiator atau pembeda dengan pesaing, maka bank perlu menciptakan diferensiasi lain sehingga dapat bertahan diantara kesesakan persaingan pasar. Secara sederhana kinerja keuangan perusahaan sesungguhnya 
bersumber pada kesetiaan konsumen. Konsumen yang setia dapat menghemat biaya 4 hingga 5 kali untuk biaya mendapatkan pelanggan baru. Kenyataan ini menjadikan tantangan tersendiri bagi perbankan, yaitu menciptakan keinginan konsumen untuk menggunakan produk dan jasa perbankan dan menjalin hubungan yang dekat antara bank dan konsumen.

Salah satu keunggulan bersaing yang paling efektif dalam bisnis berkarakteristik jasa adalah membina hubungan erat dengan konsumen. Akhir-akhir ini perusahaan berusaha untuk membangun hubungan yang dekat dengan konsumennya. Hubungan yang dekat dengan konsumen dalam jangka panjang akan mendorong pihak-pihak yang terlibat dalam hubungan menemukan cara-cara terbaik dalam berinteraksi sehingga relationship cost dapat dikurangi. Dengan hubungan yang saling memuaskan kedua pihak, maka biaya transaksi yang muncul akibat peralihan konsumen ke penyedia jasa baru dapat dihindari (Gronroos, 1994).

Produk dan jasa perbankan merupakan bisnis yang didasarkan pada kepercayaan sehingga lebih rentan terhadap kesalahan-kesalahan dalam proses penyampaiannya. Ketika perusahaan memiliki huhungan yang dekat dengan perusahaan, konsumen cenderung lebih mudah memaafkan kesalahan yang terjadi. Oleh karena itu agar tercipta hubungan yang dekat dengan konsumen diperlukan kepercayaan konsumen sebagai elemen kuncinya. Hubungan yang erat antara perusahaan dan konsumen dapat mempengaruhi respon konsumen (Guenzi dan Peloni, 2003)

Industri perbankan terutama dalam produk-produk consumer banking bersaing dengan ketat untuk mempertahankan nasabah mereka agar tidak beralih ke bank lain yang menawarkan layanan serupa. Masalah kepercayaan mengemuka ketika semakin banyak pilihan produk dan merek di pasar disertai dengan semakin sempitnya waktu yang tersedia bagi konsumen. Selain itu, terbatasnya informasi yang disediakan oleh bank mengakibatkan konsumen hanya dapat bersandar pada nama besar. Oleh karena itu, penelitian ini bermaksud utuk mengkaji pengaruh kepercayaan konsumen terhadap kesetiaan nasabah bank.

\section{TELAAH LITERATUR DAN PENGEMBANGAN HIPOTESIS}

Pada dasarnya konsumen memiliki kedaulatan untuk memutuskan produk mana yang hendak dibeli tanpa ada paksaan atau tuntunan dari pihak eksternal (Gronow dan Warde, 2001). Namun demikian yang terjadi adalah nama besar merek seringkali menjadi satu-satunya sumber informasi konsumen dalam keputusan pembelian. Kondisi ini menunjukkan bahwa konsumen menjadi pihak yang lemah dalam proses pertukaran. Konsumen menjadi terbawa oleh arus informasi yang diciptakan oleh pemasar. Pada tahap tertentu, konsumen menjadi sangat pasif dan dengan mudah mempercayai semua informasi yang disampaikan pemasar. Kondisi ini membuat salah satu pihak dalam proses pertukaran menjadi tidak berdaya dan adanya kepercayaan akan menciptakan rasa aman dan kredibel sehingga mengurangi persepsi konsumen akan risiko dalam pertukaran. Perusahaan perlu menciptakan kondisi yang lebih stabil, lebih mudah saling memprediksi perilaku patner sehingga konsumen menjadi enggan untuk berganti penyedia produk (Turnbull et al. dalam Bennet dan Gabriel, 2001).

Morgan dan Hunt (1994) mendefinisikan kepercayaan sebagai suatu kondisi ketika salah satu pihak yang terlibat dalam proses pertukaran yakin dengan keandalan dan integritas pihak yang lain. Definsi Morgan dan Hunt sejalan dengan pendapat Moorman et al. (dalam Morgan dan Hunt, 1994) bahwa kepercayaan adalah kesediaan atau kerelaan untuk bersandar pada rekan yang terlibat dalam pertukaran yang diyakini. Kerelaan merupakan hasil dari sebuah keyakinan bahwa pihak yang terlibat dalam pertukaran akan memberikan kualitas yang konsisten, kejujuran, bertanggung jawab, ringan tangan dan berhati baik. Keyakinan ini akan menciptakan sebuah hubungan yang dekat antar pihak yang terlibat pertukaran.

Dalam riset Costabile (1998) kepercayaan atau trust didefinisikan sebagai persepsi akan kehandalan dari sudut pandang konsumen didasarkan pada pengalaman, atau lebih pada uruturutan transaksi atau interaksi yang dicirikan oleh terpenuhinya harapan akan kinerja produk dan 
kepuasan. Ciri utama terbentuknya kepercayaan adalah persepsi positif yang terbentuk dari pengalaman.

Beberapa riset berhasil menemukan hubungan kepercayaan antara konsumen dengan merek mempengaruhi keputusan pembelian konsumen. Merek toko dan merek privat menjadi semakin populer karena konsumen lebih mempercayai bahwa produk dengan merek tersebut memiliki kualitas yang lebih tinggi (Miguel et al. 2002). Selanjutnya, Delgado et al. (2000) mengindikasikan kepercayaan konsumen mempengaruhi kesetiaannya.

Achroll (dalam Bennet dan Gabriel, 2003) berpendapat baahwa dalam dunia bisnis, kepercayaan antar perusahaan (buyer-seller) membantu dalam menentukan indikator-indikator yang berkaitan dengan kinerja seperti jangkauan pertukaran informasi, penyelesain masalah bersama, kepuasan atas hasil-hasil aktivitas yang telah dilakukan dan semakin besarnya motivasi dalam implementasi hasil-hasil keputusan. Adanya kepercayaan akan menciptakan rasa aman dan kredibel dan mengurangi persepsi konsumen akan resiko dalam pertukaran (Selnes, 1988 dalam Bennet dan Gabriel, 2003). Hal ini berhasil dibuktikan oleh Walter et al.(2000) dalam Bennet dan Gabriel (2003) tentang hubungan kepercayaan antar perusahaan. Walter et al. (2000) dalam Bennet dan Gabriel (2003) membuktikan bahwa kepuasan konsumen akan mempengaruhi kepercayaan konsumen dalam hubungan pertukaran industri.

Menurut Luarn dan Lin (2003) kepercayaan adalah sejumlah keyakinan spesifik terhadap integritas (kejujuran pihak yang dipercaya dan kemampuan menepati janji), benevolence (perhatian dan motivasi yang dipercaya untuk bertindak sesuai dengan kepentingan yang mempercayai mereka), competency (kemampuan pihak yang dipercaya untuk melaksanakan kebutuhan yang mempercayai) dan predictability (konsistensi perilaku pihak yang dipercaya).

Berdasarkan temuan empiris dan teori tentang kepercayaan diatas dirumuskan beberapa hipotesis sebagai berikut :

$\mathrm{H}_{1}$ Integritas bank mempengaruhi kepercayaan nasabah terhadap bank

$\mathrm{H}_{2} \quad$ Kredibilitas bank mempengaruhi kepercayaan nasabah terhadap bank

$\mathrm{H}_{3}$ Benevolence mempangaruhi kepercayaan konsumen terhadap bank

$\mathrm{H}_{4}$ Kepercayaan mempengaruhi kesetiaan nasabah.

\section{METODA PENELITIAN}

Penelitian ini melibatkan 220 responden yang merupakan nasabah berbagai bank di Surabaya baik bank negara maupun bank swasta. Responden yang dipilih adalah mereka yang memenuhi syarat sebagai anggota sampel yaitu bekerja dan bertempat tinggal di Surabaya, telah menjadi nasabah bank selama lebih dari 5 tahun, berusia 25 hingga 60 tahun. Sampel diambil dengan metode snowball sampling. Teknik snowball sampling dipilih karena kendala memperoleh daftar nasabah bank sehingga pengambilan sampel secara acak tidak dimungkinkan. Meskipun pengambilan sampel dilakukan dengan teknik non random, generalisasi hasil masih dimungkinkan bila didukung dengan jumlah sampel yang besar.

Selanjutnya responden diminta kesediaannya untuk mengisi kuesioner. Data dikumpulkan dengan menggunakan skala Likert dimana nilai 5 mewakili sangat setuju dan nilai 1 mewakili sangat tidak setuju. Data yang terkumpul dianalisis dengan menggunakan teknik model persamaan struktural. Model persamaan struktural adalah teknik analisis yang merangkaikan beberapa variabel independen dan dependen untuk mengetahui pengaruh dari masing-masing variabel tersebut. Penggunaan alat statistik ini didasarkan pada beberapa pertimbangan yaitu: alat ini menyediakan model yang secara langsung dapat memproses sejumlah hubungan antar variabel secara bersamaan sekaligus efisiensi dalam statistik; dan kemampuan alat ini untuk menilai hubungan yang ada diantara variabel secara komprehensif. Data ditabulasi dengan program SPSS versi 11 dan kemudian diolah dengan program AMOS versi 5.

\section{ANALISIS HASIL DAN PEMBAHASAN}

Model diuji terlebih dahulu dengan software Amos versi 5 untuk menentukan apakah model penelitian yang diatas sesuai dengan data yang digunakan. Berdasarkan tingkat signifikansi 
sebesar 0.487, dan nilai Chi-square sebesar 96.803, indeks Cmin/df, GFI, TLI, RMSEA, CFI diterima pada rentang nilai yang disyaratkan seperti ditunjukkan pada tabel 1 dibawah ini :

Tabel 1

Goodness of Fit Persamaan Model Struktural

\begin{tabular}{lclc}
\hline \multicolumn{1}{c}{ Indikator } & Batas Penerimaan & Hasil & Keterangan \\
\hline Chi Square & diharapkan kecil & 96.803 & \\
Probabilitas & $>0.05$ & 0.487 & Baik \\
Cmin/DF & $<2$ & 0.998 & Baik \\
RMSEA & $<0.08$ & 0.000 & Baik \\
GFI & $>0.90$ & 0.947 & Baik \\
CFI & $>0.95$ & 1.000 & Baik \\
TLI & $>0.95$ & 1.000 & Baik \\
\hline
\end{tabular}

Selanjutnya, terdapat empat hipotesis yang diuji dalam penelitian ini. Hipotesis pertama, bahwa integritas mempengaruhi kepercayaan secara signifikan berhasil dibuktikan dengan nilai critical ratio sebesar 3.443 pada tingkat signifikansi sebesar 0.000 . Hipotesis kedua yang menyatakan bahwa kredibilitas mempengaruhi kepercayaan secara signifikan berhasil dibuktikan dengan nilai critical ratio sebesar 3.096 pada tingkat signifikansi sebesar 0.002. Hipotesis ke tiga bahwa benevolence akan mempengaruhi kepercayaan berhasil dibuktikan secara signifikan dengan nilai critical ratio sebesar 4.264 pada taraf signfikansi sebesar 0.000 . Hipotesis ke empat yang menyatakan bahwa kepercayaan akan mempengaruhi kesetiaan nasabah juga berhasil dibuktikan dengan nilai critical ratio sebesar 10.486 pada taraf signifikansi sebesar 0.000

\begin{tabular}{|c|c|c|c|c|c|}
\hline Simbol & Hipotesis & Estimate & C.R & $\mathbf{P}$ & Ket. \\
\hline $\mathrm{H}_{1}$ & $\leftarrow$ Integrity & 0.264 & 3.443 & 0.001 & Terbukti \\
\hline & $\leftarrow$ Credibility & 0.201 & 3.096 & 0.002 & Terbukti \\
\hline & $\leftarrow$ Benevolence & 0.327 & 4.264 & 0.000 & Terbukti \\
\hline $\mathrm{H}_{4}$ & $\leftarrow$ Trust & 0.079 & 10.486 & 0.000 & Terbukti \\
\hline
\end{tabular}

Hasil uji hubungan kausalitas menunjukkan bahwa integritas mempengaruhi kepercayaan merek sebesar 0.281. Fakta ini menandakan bahwa penilaian konsumen terhadap integritas karyawan bank mempengaruhi kepercayaan, untuk menabung atau aktivitas intermediasi lainnya. Kesan yang diterima oleh nasabah akan integritas karyawan ketika mereka menghadapi masalah misalkan apakah karyawan menampakkan nilai-nilai dan prinsip-prinsip perbankan yang benar atau apakah setiap masalah yang dihadapi nasabah diselesaikan oleh karyawan bank sesuai dengan konteks dan sistem yang berlaku akan menentukan penilaian nasabah apakah bank dapat dipercaya atau tidak. Kesan-kesan tersebut menjadi acuan penilaian nasabah dalam menentukan apakah bank melakukan praktik-praktik yang jujur dalam menjalankan fungsi intermediasinya.

Hasil uji hubungan kausalitas menujukkan bahwa kredibilitas mempengaruhi kepercayaan merek sebesar 0.201. Kredibilitas diartikan sebagai kemampuan perusahaan untuk memenuhi harapan nasabah. 
Sejauhmana pengalaman perusahaan dalam industri tersebut dinilai sebagai sedalam apakah keahlian perusahaan dalam layanan jasanya oleh nasabah. Dalam konteks perbankan, usia bank atau karyawan bank yang dinilai senior dalam bisnis perbankan, membentuk kesan dalam alam pikir nasabahnya bahwa bank tersebut memiliki keahlian yang mencukupi sehingga layak dipercaya.

Hasil uji hubungan kausalitas menujukkan bahwa benevolence mempengaruhi kepercayaan merek sebesar 0.346 . Hal terpenting dalam industri jasa perbankan adalah adanya empati karyawan yang dapat dirasakan oleh nasabah. Sikap perhatian (concern) yang mendalam karyawan bank pada nasabahnya menjadi tanda apakah bank layak dipercaya atau tidak. Perhatian karyawan terhadap nasabah merupakan indikator bagi nasabah bahwa bank memiliki kebijkan-kebijakan yang berorientasi pada nasabah. Bagi nasabah, kebijkan semacam ini dinilai penting mengingat faktor risiko yang harus ditanggung nasabah ketika kinerja bank menjadi buruk.

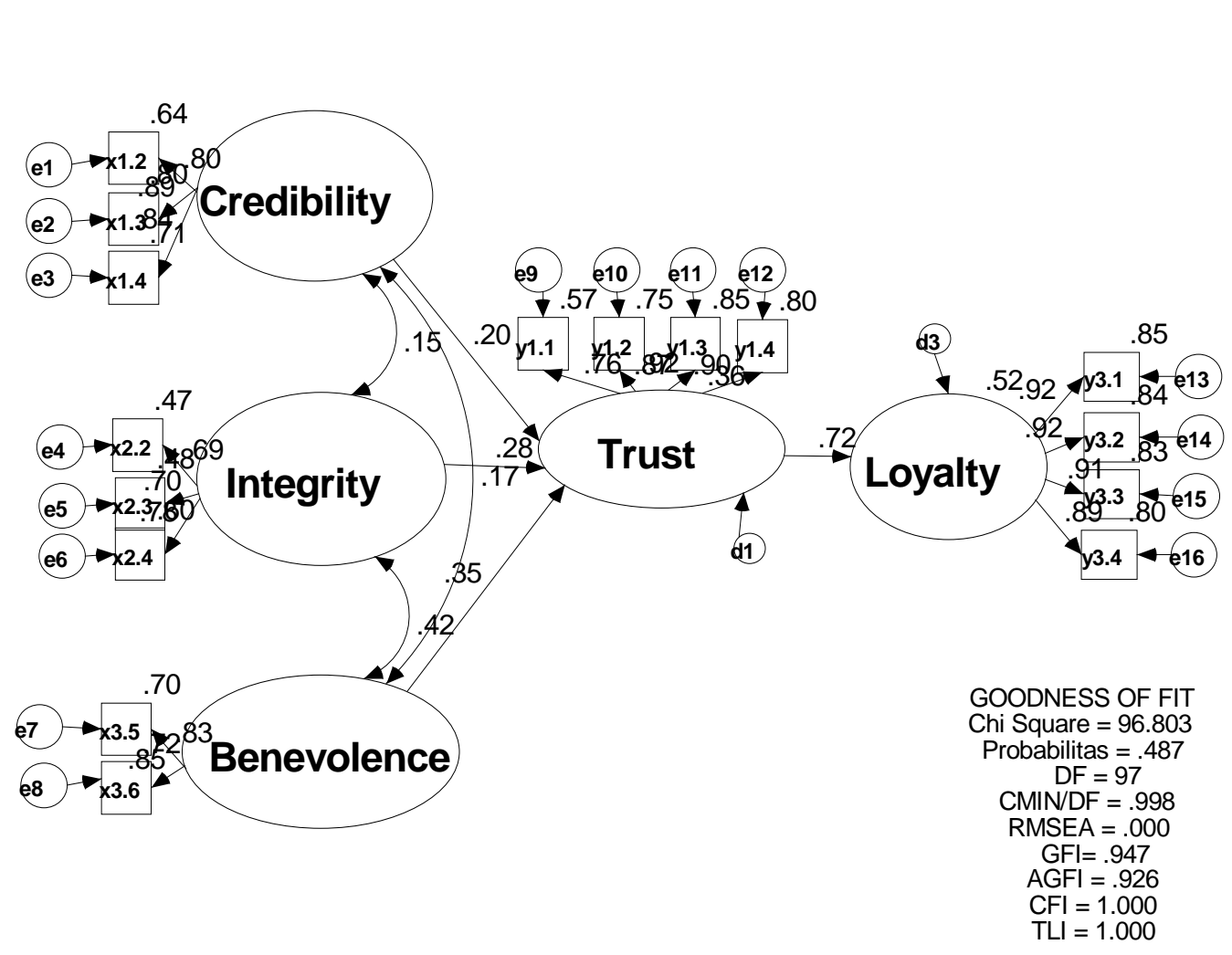

Gambar 1

Hasil Uji Kausalitas

Hasil uji hubungan kausalitas menunjukkan bahwa kepercayaan mempengaruhi kesetiaan sebesar 0.725. Temuan ini sesuai dengan bukti-bukti empiris bahwa suatu hubungan jangka panjang memang didasari adanya kepercayaan diantara pihak-pihak yang terlibat. Konsumen akan setia pada perusahaan, merek atau produk yang telah mereka percaya (Delgado et al., 2003). Seseorang akan mempercayai pihak lain ketika ada cukup bukti dan alasan bahwa pihak tersebut sungguh layak untuk dipercaya. Oleh karena itu, kepercayaan merupakan perantara yang menjembatani hasil-hasil kinerja ekonomi dengan hubungan jangka panjang perusahaan-konsumen (Geyskens et al., 1998:243). Artinya kinerja keuangan perbankan saja tidak mampu dengan sendirinya menciptakan nasabah yang setia namun diperlukan adanya emosi dalam diri nasabah 
dalam bentuk rasa aman, rasa yakin, bahkan rasa senang terhadap layanan bank yang merupakan ekspresi kepercayaan untuk membuat nasabah setia pada bank.

Demikian juga dengan publikasi dan berbagai gebyar yang dilansir oleh berbagai bank yang besar besar dan memakan biaya yang begitu tinggi belum tentu mampu untuk menarik kepercayaan dan loyalty dari para nasabah. Disini terbukti bahwa menurut Ferrinadewi ( 2005 ) pengalaman memperoleh pelayanan, perhatian dan hasil yang menguntungkan dalam waktu tertentu lebih berbicara untuk tetap mengikat para nasabah menjadi nasabah yang setia.

\section{SIMPULAN}

Kepercayaan merupakan salah satu bentuk perasaan. Kepercayaan merupakan satu proses kognitif yang terjadi dalam benak manusia. Emosi konsumen berperan aktif dalam formasi kepercayaan antara nasabah dan bank.. Kunci dari hubungan kepercayaan ini adalah pengalaman. Jika pengalaman positif sering dialami konsumen maka konsumen menaruh kepercayaan pada produk dan sebaliknya. Dapat diartikan juga bahwa kepercayaan adalah suatu keadaan sebagai hasil hubungan yang terbangun dalam jangka waktu tertentu. Kepercayaan merupakan variabel yang menjembatani kinerja keuangan perusahaan dengan keinginan nasabah untuk tetap setia pada bank.

\section{DAFTAR PUSTAKA}

Bennet, Roger, dan Helen Gabriel, (2001),"Reputation, Trust and Supplier Commitment The Case Old Shipping Company/Seaport Relations," Journal "of Business and IndustrialMarketing, Vol. 16 p. 424-438.

Chiou, Jyh-Shen, Cornelia Droge dan Sangphet Hanvanich, (2002), "Does Customer Konwledge Affect How Loyalty is Form ?," Journal of Service Marketing, vol.5 no,2, p. 121-131.

Chow, Simeon, dan Reed Holden, (1997), "Toward An Understanding Of Loyalty : The Moderating Role Of Trust," Journal of Managerial Issues, Vol. IX no. 3, p. $275-29$

Costabile, Michele, (2003), A Dynamic Model of Customer Loyalty, Working Paper.

Delgado-Ballester, Ellena dan Josse-Luis Munuera Allmeman dan Maria JesusYague Guelen, (2003), "Development and Validation of Brand Trust Scale," International Journal of Market Research, Vol 45, p. 35-53.

Ferrinadewi, Erna, (2005a), "Hubungan Kepercayaan Antara Konsumen dan Merek : Studi Eksplorasi Konsumen Kosmetik di Surabaya," Jurnal Akuntansi, Manajemen Bisnis dan Sektor Publik, vol.1 no. 3, p.230-241.

Geyskens, Steenkamp, J.E.M dan Kumar N, (1998), "Generalizations About Trust in Marketing Chanel Relationship Using Meta-Analysis International" Journal of Research in Marketing, vol. 15, p.223-248.

Gronow, Jukka dan Allan Warde, (2001), Ordinary Consumption, London.

Gronroos, Christian, (1994),"From Marketing Mix to Relationship Marketing : Toward a Paradigm Shift in Marketing", Journal of Management Decision, vol. 32, no. 2, p. 4-20. 
KINERJA, Volume 10, No.1, Th. 2006: Hal. 50-56

Guenzi, Paolo dan Ottavia Pelloni., (2003), Interpersonal Relationship and Customer Loyalty : A Comprehensive Model and Empirical Investigation, Working Paper, Instituto di Economia e Gestione delle Impresse, Universita Commerciale Luigi Bocconi, Millano, Italy.

Luarn, Pin dan Hsin-Hui lin, (2003), "A Customer Loyalty Model For E Service Context," Journal of Electronic Commerce Research, Vol. 4, no. 4, p. 156-167.

Morgan, Robert M. dan Shelby D. Hunt, (1994), "The Commitment -Trust Theory of Relationship Marketing", Journal of Marketing, Vol. 58, p. 20-38. 